\title{
OZDOBY STROJU WYKONANE Z PACIORKÓW W KULTURZE WIELBARSKIEJ
}

SŁowA KLuczowe: kultura wielbarska, paciorki, kolie, dekoracje, aplikacje KEYwords: Wielbark culture, beads, necklaces, decorations, applications

Badania nad paciorkami w kulturze wielbarskiej były podejmowane kilkukrotnie. Typologiczne opracowania omawianych zabytków rozpoczęły się już w XIX w. Wówczas Otto Tischler dokonał podziału materiału z byłych Prus Wschodnich (Tischler 1879), co nie dotyczyło wyłącznie materiałów później tak nazywanej kultury wielbarskiej, ale jednak po części. Autor ten wśród paciorków bursztynowych wydzielił typy cylindryczne, dwustożkowate, bębenkowate, poliedryczne, czworokątne i ósemkowate. W dalszej kolejności, podzielił szklane paciorki na jednobarwne, wielobarwne i ze złotą wkładką (Tischler 1879: 234-243).

Następnie materiał z obszaru Pomorza został opracowany przez Ericha Blumego, który wyróżnił spośród paciorków szklanych i bursztynowych 37 typów. Podział tych zabytków został oparty przede wszystkim o kryteria barwy i kształtu (Blume 1912; 1915).

Dopełnieniem opracowań omawianej kategorii zabytków pochodzących z Pomorza są prace Ernsta Jungklausa (1924), Hansa Jürgena Eggersa (1940) i Władysława Łęgi (1958).

Klasyfikacji technologicznej paciorków z Polski północnej dokonała Teresa Stawiarska, która podzieliła zabytki na sześć grup (1985). Głównym kryterium tej systematyzacji stała sie technika formowania paciorków.

W rozwoju badań nad paciorkami bardzo istotne znaczenie mają studia Magdaleny Mączyńskiej (np. 1972; 1977). Spośród prac tej autorki, dotyczących wspomnianej kategorii zabytków, najistotniejsze jest opracowanie typologiczne paciorków z terenu środkowoeuropejskiego Barbaricum, uwzględniające także znaleziska z obszaru kultury wielbarskiej (Tempelmann-Mączyńska 1985a). 
Analiza oparta na tej bazie źródłowej pozwoliła badaczce wyróżnić, spośród paciorków szklanych, bursztynowych, glinianych, kościanych i metalowych, 61 grup. Dodatkowo, w rozdziale poświęconym funkcji paciorków, M. Mączyńska zwróciła uwagę na rozmaite ich wykorzystanie w obszarze dekoracji stroju (Tempelmann-Mączyńska 1985a: 141-144).

Wszystkie przedstawione prace sprowadzają się do klasyfikacji paciorków w ramach podziału typologicznego lub technologicznego. Dotychczas nie podjęto próby szczegółowej analizy całych zestawów paciorków, które tworzyły rozmaite dekoracje stroju kultury wielbarskiej.

Przystąpienie do opracowania tematu ozdób wykonanych z paciorków było podyktowane ogromną bazą źródłową, której dostarczają cmentarzyska kultury wielbarskiej ${ }^{1}$. Wspomniana jednostka archeologiczna stosowała birytualny obrządek pogrzebowy. Oznacza to, że praktykowała kremację i inhumację zwłok (Wołągiewicz 1981: 151; Kokowski 2004: 227; 2006: 190). W następstwie, pochówki ciał niespalonych ułatwiają badania nad rekonstrukcją tego typu ozdób, ponieważ realne jest uchwycenie dokładnego położenia zabytków w grobie ${ }^{2}$. W rezultacie możliwe staje się podjęcie próby odtworzenia pierwotnego układu kompozycji paciorków, a zatem określenia ich funkcji w ramach dekoracji stroju pogrzebowego.

Najczęściej paciorki odkrywane na stanowiskach kultury wielbarskiej interpretowane są jako ozdoby szyi tworzące „kolię”’3. W literaturze przedmiotu pojęcie to powszechnie stosuje się do wszelkich skupisk paciorków rejestrowanych w grobach niezależnie od miejsca ich znalezienia np. na poziomie szyi, klatki piersiowej, głowy, pasa, rąk czy nóg. Ponadto tym terminem określane są zarówno pojedyncze paciorki jak i całe ich pasma ${ }^{4}$.

Tymczasem każdy układ paciorków, odkrywany na wspomnianych poziomach w grobie, pełnił funkcję dekoracyjną określonej części ciała. W terminologii archeologicznej pojęcie „kolia” oznacza zwarty naszyjnik złożony z różnych paciorków i wisiorków (Kostrzewski 1964: 440). Stosowanie terminu „kolia” do dowolnej kompozycji omawianych zabytków nie jest zgodne z jego definicją.

\footnotetext{
${ }^{1}$ Praca napisana w ramach projektu sfinansowanego ze środków Narodowego Centrum Nauki, przyznanych na podstawie decyzji numer DEC-2015/19/N/HS3/02151.

${ }^{2}$ Uwaga ta odnosi się przede wszystkim do zespołów odkrytych w grobach o nienaruszonym układzie zabytków. Tzw. naruszone lub wyrabowane obiekty uniemożliwiają dokładne określenie typu dekoracji złożonej z paciorków. Dodatkowo, w takich przypadkach zawsze istnieje ryzyko niekompletnego zestawu zabytków.

${ }^{3} \mathrm{~W}$ niniejszej pracy nie zostały uwzględnione paciorki odkryte np. w północnej lub południowej części jamy grobowej. Jest to podyktowane miejscem zdeponowania tych znalezisk, które nie były bezpośrednio związane ze strojem osoby pochowanej w grobie. W następstwie te zabytki zakwalifikowano jako „dary”.

${ }^{4}$ Przez termin ,pasmo paciorków” mam na myśli kompozycje paciorków znajdujących się w ułożeniu ciągłym, tworzące jeden zabytek.
} 
Odwołując się do etymologii tego słowa należy podkreślić, że pochodzi ono od francuskiego wyrazu collier, które oznacza naszyjnik lub obrożę. Podobnie w przypadku łacińskiego słowa collare określającego takie rzeczowniki jak kołnierz, obrożę, naszyjnik lub łańcuch. W języku polskim wyraz kolia odnosi sie do ozdób będących naszyjnikami zaopatrzonymi w kamienie szlachetne lub ich imitację, które są ułożone w bogatą, dekoracyjną kompozycję (Sobol 1995: 323). Wszystkie definicje słowa „kolia” nawiązują do ozdoby w postaci wieloelementowego naszyjnika. W konsekwencji należałoby stosować to pojęcie wyłącznie do pasm paciorków odkrywanych w grobach na poziomie szyi i klatki piersiowej osób zmarłych. Na wyróżnienie tego typu ozdób zwrócili już uwagę skandynawscy badacze. Analizując materiał pochodzący ze stanowiska w Skovgårde, położonego $\mathrm{w}$ południowej części Zelandii, wydzielili aż trzy typy kolii (Ethelberg 2000: 92-102). Pierwszy z nich, nawiązuje do krótkich ozdób zarejestrowanych przy szyi (Halskette). Drugi, do długich pasm paciorków odkrywanych na poziomie klatki piersiowej (Brustkette). Ostatni typ odnosi się do zabytków lokalizowanych przy głowie (Haarkette), które pierwotnie zostały wpięte we włosy zmarłej jako element wianka.

Niestety, w języku polskim jedynym określeniem ozdoby z paciorków zachowanej przy szyi lub w obrębie klatki piersiowej jest termin „kolia”. Nim należałoby definiować pasma pierwotnie zakładane na szyję oraz te kompozycje paciorków, które zostały rozwieszone na szatę za pomocą fibul i w ten sposób ja go stosuję. W obu przypadkach zasadniczą funkcją omawianych ozdób była dekoracja określonej części ciała czyli obszaru szyi i klatki piersiowej ${ }^{5}$.

Przykład kolii noszonej na szyi przedstawia układ zabytków odkryty w grobie 98 z cmentarzyska w Pruszczu Gdańskim, stan. 10 (Tempelmann-Mączyńska 1985a: 308; Pietrzak 1997: 22, tabl. CLXX: 2). Pochowana w tym grobie kobieta została wyposażona $\mathrm{w}$ dwa pasma paciorków zarejestrowanych na poziomie szyi i klatki piersiowej (ryc. 1: 1). Ponadto w grobie tym zostały odkryte trzy zapinki lecz umieszczono je przy stopach, a nie na poziomie ramion czy klatki piersiowej osoby zmarłej. Należy wykluczyć w tym przypadku możliwość rozwieszenia kolii za pomocą fibul na odzież gdyż nie wystąpiły na tym samym poziomie, co paciorki. W następstwie, wspomniane kolie pierwotnie zostały zawieszone na szyi zmarłej.

Wykorzystanie zapinek do podtrzymywania kolii na szacie prezentują np. układy paciorków z grobu 89 w Opaleniu, pow. tczewski oraz z obiektu 342 w Weklicach, pow. elbląski (Tuszyńska 2003: 307; 2007: 151-152; Natuniewicz-Sekuła, Okulicz-Kozaryn 2011: 78; Tuszyńska i in. 2016: 18-19). Odkryte w nich długie pasma paciorków rozciągały się od poziomu ramion do klatki

${ }^{5}$ Analizę kolii wykonanych z paciorków w kulturze wielbarskiej omawiam w innym miejscu (por. Żyto, w druku a). 
piersiowej. Obie kolie z paciorków rozpoczynały się od fibul umieszczonych pierwotnie na ramionach osób zmarłych (ryc. 1: 2). Jednoznaczne układy zapinek względem kolii niewątpliwie wskazują na wykorzystanie fibul jako mocowania pasm paciorków do szat.

$\mathrm{Na}$ cmentarzyskach wielbarskich rejestrowane są obiekty, w których wspomniana grupa zabytków znajduje się w różnych częściach jamy grobowej, co

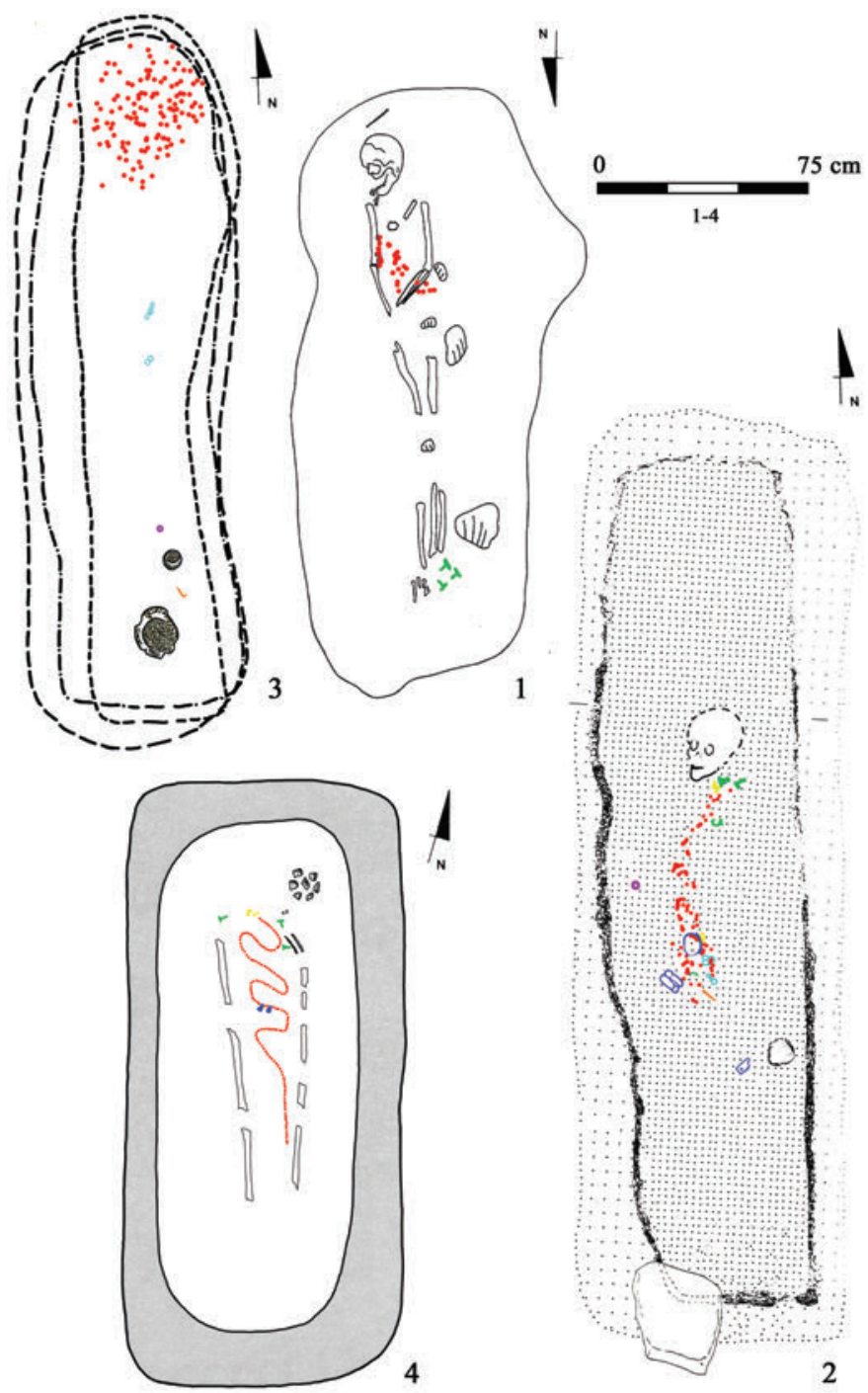

Ryc. 1. Plany grobów z zaznaczonym układem paciorków. 1. Pruszcz Gdański, stan. 10, grób 98 (Pietrzak 1997: tabl. XXVIII); 2. Opalenie, grób 89 (Tuszyńska i in. 2016: 18); 3. Odry, grób 121 (Kmieciński i in. 1968: tabl. XLI); 4. Kowalewko, grób 84 (Skorupka 2001: tabl. 24). 
jednoznacznie wskazuje na ich rozmaite wykorzystanie w ramach ogólnego pojęcia dekoracji stroju. W pierwszej kolejności należy wymienić nieregularne, wręcz rozproszone, układy paciorków odkrywane od szyi do poziomu pasa osoby zmarłej. Tego typu położenie omawianych ozdób w nienaruszonych grobach jest interpretowane jako aplikacja na odzież (por. Natuniewicz-Sekuła, Okulicz-Kozaryn 2011: 78). Oznacza to, że paciorki przyszywano do określonej części stroju lub tkaniny, którą pokryto ciało, tak aby tworzyły ozdobny wzór. Tego typu układy zabytków znane są np. z grobu 121 w Odrach, pow. chojnicki (ryc. 1: 3), czy grobu 12 ze stanowiska 5 w Pruszczu Gdańskim, pow. gdański (tabl. 1: 1, 2) (Kmieciński i in. 1968: 65, 72, 73, 78, 85, tabl. XIII; Tempelmann-Mączyńska 1985a: 301; Pietrzak i in. 2015: 22-23, tabl. IX).

Kolejnym, odmiennym układem są paciorki w kompozycji pionowej. W grobach wielbarskich zostały uchwycone na poziomie szyi i klatki piersiowej, czasami rozkład zabytków sięgał do poziomu kolan. Tego typu usytuowanie paciorków w pochówkach zostało zinterpretowane jako zjawisko rozerwania kolii i złożenia jej na zwłokach (por. Skorupka 2001: 227). Spośród materiału kultury wielbarskiej najczytelniej pionowe układy paciorków zostały uchwycone na stanowisku w Kowalewku, pow. obornicki ${ }^{6}$. Kompozycje paciorków odkryte w linii pionowej zarejestrowano na tym cmentarzysku w czterech grobach. W pierwszym z nich, obiekcie 84, znaleziono 249 paciorków wykonanych ze szkła i bursztynu ${ }^{7}$ (Skorupka 2001: 34, tabl. 25: 84). Pasmo rozciągało się od szyi aż do poziomu nóg osoby zmarłej (ryc. 1: 4). Można przyjąć założenie, że omawiana kompozycja pierwotnie była kolią. Przemawiają za tym, wkomponowane w centralną część tego układu, dwa wiaderkowate wisiorki. W przypadku połączenia całego pasma tak, aby uzyskało formę kolii, te metalowe dodatki wyeksponują jej środkową część. Tego typu rozmieszczenie zabytków w koliach jest dobrze rozpoznane $\mathrm{w}$ materiale kultury wielbarskiej. Ozdoby metalowe w koliach wystąpiły np. w grobach 89, 134 i 187 w Linowie, pow. grudziądzki; w grobach 17 i 34 w Pruszczu Gdańskim, stan. 5 czy w grobie 30 w Ulkowych, oba w pow. gdańskim (Pietrzak 1998: 122; Tuszyńska 2005: 19-20, 84, tabl. XV: 30; Kurzyńska 2015: 35-36, 45-46, 57-58, tabl. XXIII, XXXIX-XL, LVII; Pietrzak i in. 2015: 24-26, tabl. XII-XV, L, LII, LIII, LIV). Należy jednak przyjąć inny sposób wykorzystania paciorków z grobu 84 z Kowalewka. Otóż równie prawdopodobne jest to, że zabytki stanowiły obszycie brzegu szaty tzn. jej otwartej części. Podobne wykorzystanie paciorków do obszycia szaty znane jest z układu zabytków odkrytych w grobie 1 w Grodzisku Mazowieckim, pow. grodziski (Barankiewicz 1959: 192-194, 216-217, ryc. 2, tabl. II-III). W obiekcie

\footnotetext{
${ }^{6}$ Por. np. układ paciorków w grobie 71 w Lubowidzu, pow. lęborski; grób 19 w Ulkowych, pow. gdański (Tempelmann-Mączyńska 1985a: 292; Wołągiewicz 1995: 19, tabl. XII: 71; Tuszyńska 2005: 16, tabl. IX).

${ }^{7}$ Wśród omawianego zbioru paciorków jeden egzemplarz został wykonany z nasiona.
} 
tym paciorki zlokalizowano na poziomie stóp osoby zmarkej. Omawiane położenie znalezisk zostało zinterpretowane jako dekoracyjne wykończenie dolnej części sukni (Tempelmann-Mączyńska 1985a: 144; 1985b: 52; 1989: 63). Następny, pionowy układ paciorków odkryty w Kowalewku zarejestrowano w grobie 201 (Skorupka 2001: 60-61, tabl. 61-63, fot. 1). Kompozycja rozciągała się od poziomu szyi do poziomu pasa (ryc. 2: 1 ; 4; tabl. 2: 2). W skład pasma wchodzi-

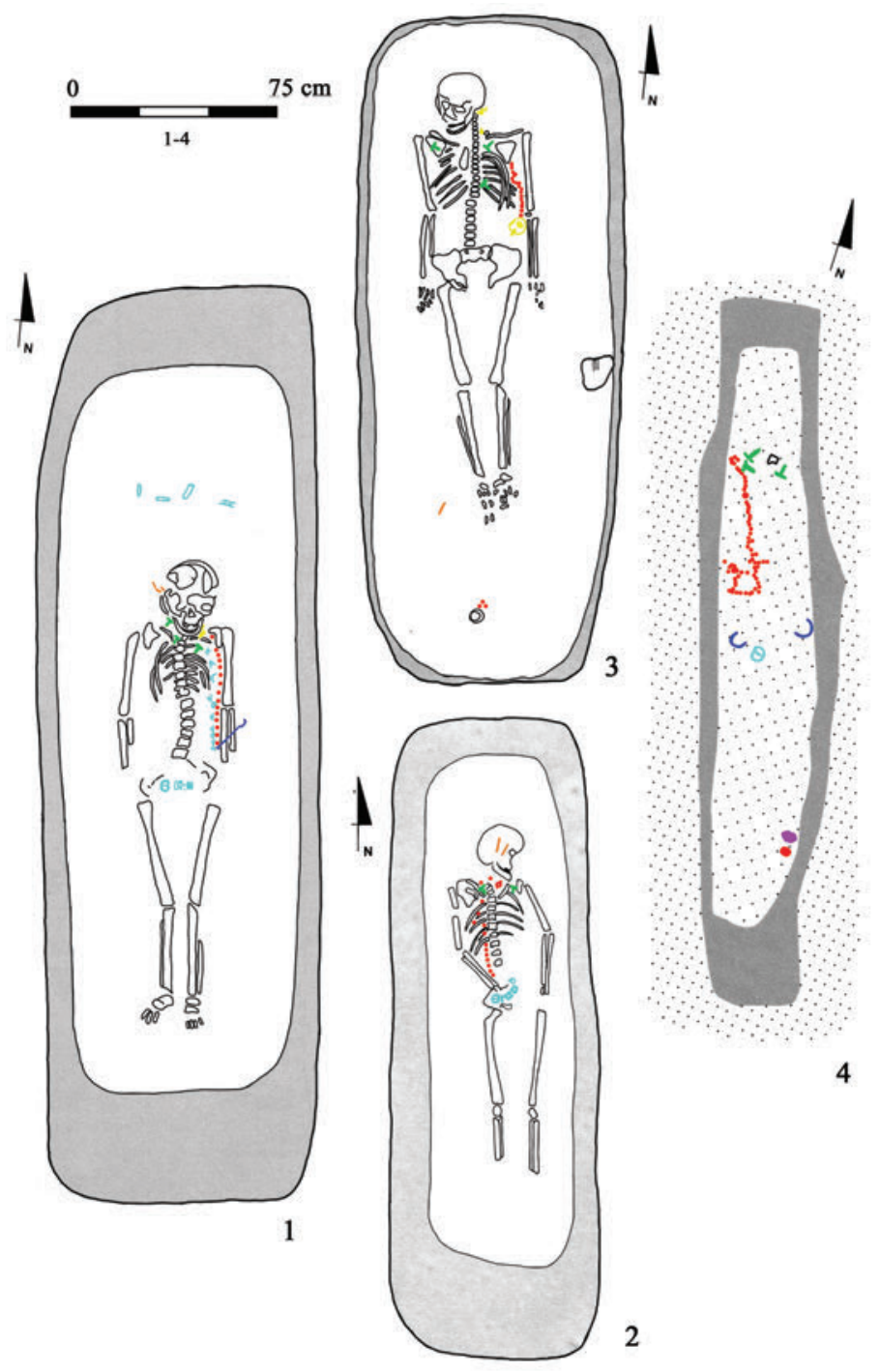

Ryc. 2. Plany grobów z zaznaczonym układem paciorków. 1. Kowalewko, grób 201 (Skorupka 2001: tabl. 60); 2. Kowalewko, grób 282 (Skorupka 2001: tabl. 85); 3. Kowalewko, grób 375 (Skorupka 2001: tabl. 118); 4. Brzyno, stan. 12, grób 102 (Strobin, Strobin 2018: ryc. 2). 
ły szklane i bursztynowe paciorki wraz z dwoma pierścieniami. W tym przypadku rozkład zabytków jednoznacznie wskazuje na ich inne wykorzystanie, niżeli w formie ozdoby, jaką jest kolia. Warto zwrócić uwagę na równoległe położenie względem tego pasma ogniwek wykonanych z brązu. Dodatkowo, w dolnej części wspomnianego układu znajdował się klucz wraz z pierścieniem zawieszonym na jednej skuwce. Warto w tym miejscu podkreślić, że złącza ogniwkowe należą do przedmiotów związanych z garniturem pasa (Madyda-Legutko 1983: 91). Znaczące jest to, że w omawianym grobie zarejestrowano sprzączkę i okucia pasa na poziomie talii. Interesujące nas ogniwka odnotowane w pionowej kompozycji nie mogły wiązać się z pasem oprawionym w sprzączkę i okucia. Zasadniczą funkcją złącz ogniwkowych w okresie rzymskim było łączenie pasa składającego się z kilku kawałków skóry (Madyda-Legutko 1983: 91). W grobie 201 z Kowalewka zabytki te również należałoby wiązać z wąskim paskiem, na którego końcu znajdował się klucz. Równoległy układ paciorków i pierścieni względem ogniwek wskazuje na wykorzystanie ich jako elementu dekoracyjnego. Ozdoby mogły zostać przyszyte do omawianego paska lub tworzyły oddzielne jednolite pasmo, które zostało połączone z ogniwkami za pomocą pierścienia przymocowanego do klucza (tabl. 2: 2). Podobne uwagi można odnieść również do grobu 282 z Kowalewka (Skorupka 2001: 78, tabl. 85). W tym obiekcie paciorki stanowiły część pionowej dekoracji rozciągającej się od poziomu szyi do poziomu pasa (ryc. 2: 2). Do stworzenia tej kompozycji wykorzystano oprócz paciorków także wisiorek, który wykonano z okucia końca pasa oraz kółek różnej formy. W przeciwieństwie do poprzedniego, omówionego układu ta forma ozdoby została połączona $\mathrm{z}$ elementami pasa złożonego na poziomie talii (tabl. 2: 1). Ostatnia pionowa kompozycja paciorków na stanowisku w Kowalewku została zarejestrowana w grobie 375. Paciorki w układzie in situ odkryto wzdłuż lewej kości ramiennej osoby pochowanej (ryc. 2: 3). Pasmo wspomnianych zabytków zostało zakończone wisiorem opasanym. Większość wisiorów opasanych, zarejestrowanych na stanowiskach w środkowoeuropejskim Barbaricum, stanowiło część kolii lub było przymocowanych do pasa (Stanek 1999: 340). Można uznać, że układ zabytków z Kowalewka pierwotnie stanowił ozdobę szyi. Uzasadnieniem tej tezy są kolie z wisiorami opasanymi odkryte np. w grobie 66 w Kamienicy Szlacheckiej, pow. kartuski czy obiekcie 277 na cmentarzysku w Weklicach (Tuszyńska 2010: 489-496; Natuniewicz-Sekuła, Okulicz-Kozaryn 2011: 81, tabl. CXX, CXXI, CCXL: 6, CCXLII: 21). Należy podkreślić, że zawartość wisiorów opasanych była rozmaita. Noszono te ozdoby z bursztynem, orzechami, pestkami, kulkami szkła, kamykami, muszlami czy bezoarami (Stanek 1999: 341). W następstwie wisiorom opasanym przypisuje się funkcję amuletów apotropaicznych (Stanek 1999: 341). Pionowa kompozycja zabytków z grobu 375 z Kowalewka zwieńczona wisiorem opasanym mogła również być ozdobą symbolicznego znaczenia. Możliwe, że złożenie jej w takim 
układzie stanowiło wyeksponowanie pasma jako formy nie tylko dekoracyjnej ale również mającej własność magiczną.

Paciorki w okresie rzymskim także wykorzystywano jako ozdobę pasa (Tempelmann-Mączyńska 1989: 63; Beilke-Voigt 1998: 83). W Kowalewku w grobach 87 i 223 (ryc. 3: 1, 2; tabl. 3: 2, 3) odkryto pasma paciorków przy zachowanych sprzączkach na poziomie talii (Skorupka 2001: 34, 35, 65, tabl. 26, 68).

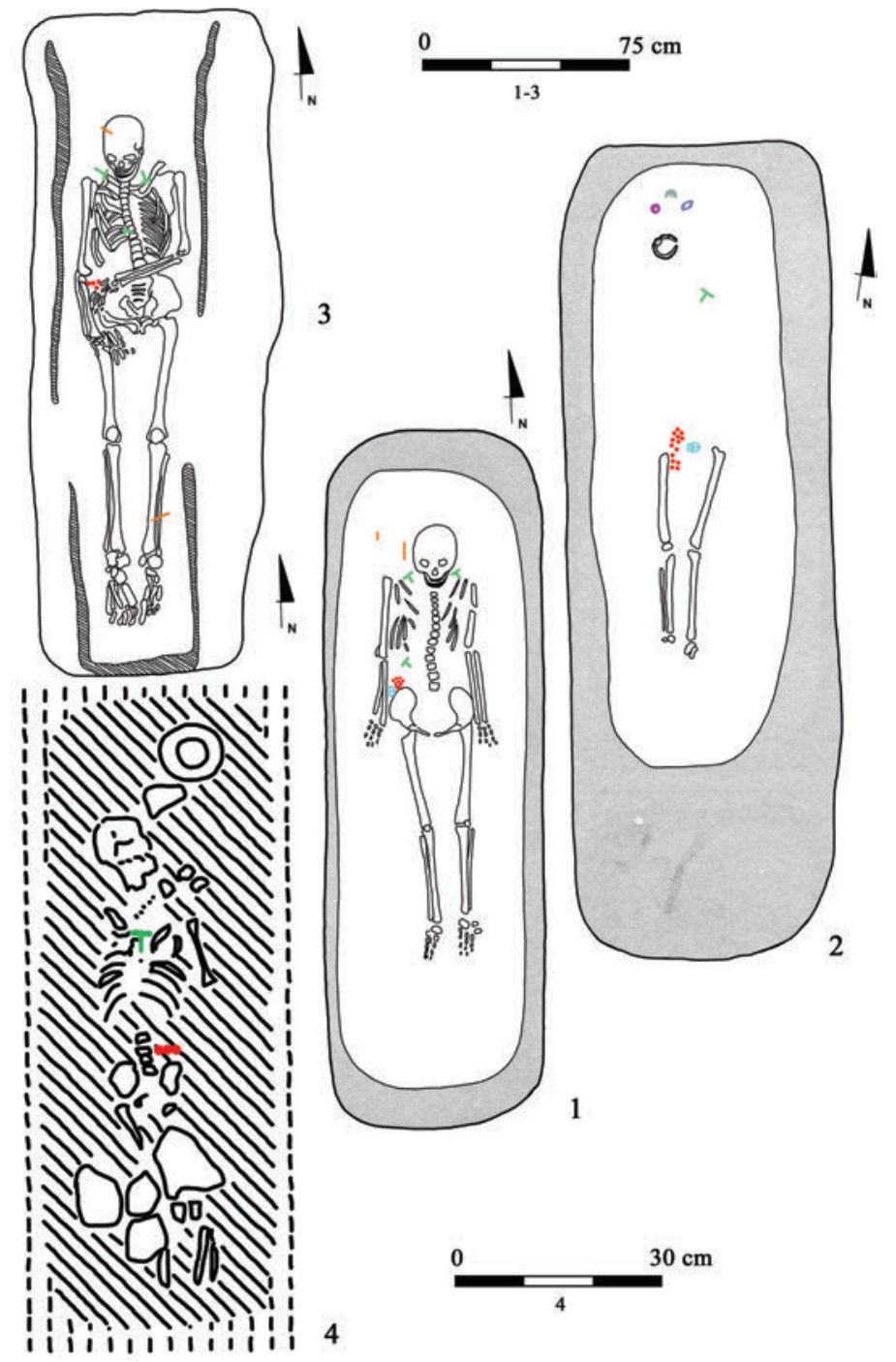

Ryc. 3. Plany grobów z zaznaczonym układem paciorków. 1. Kowalewko, grób 87 (Skorupka 2001: tabl. 26); 2. Kowalewko, grób 223 (Skorupka 2001: tabl. 68); 3. Pruszcz Gdański, stan. 10, grób 428 (Pietrzak 1997: tabl. CXXVIII); 4. Cecele, grób 17A (Jaskanis 1996: tabl. III). 


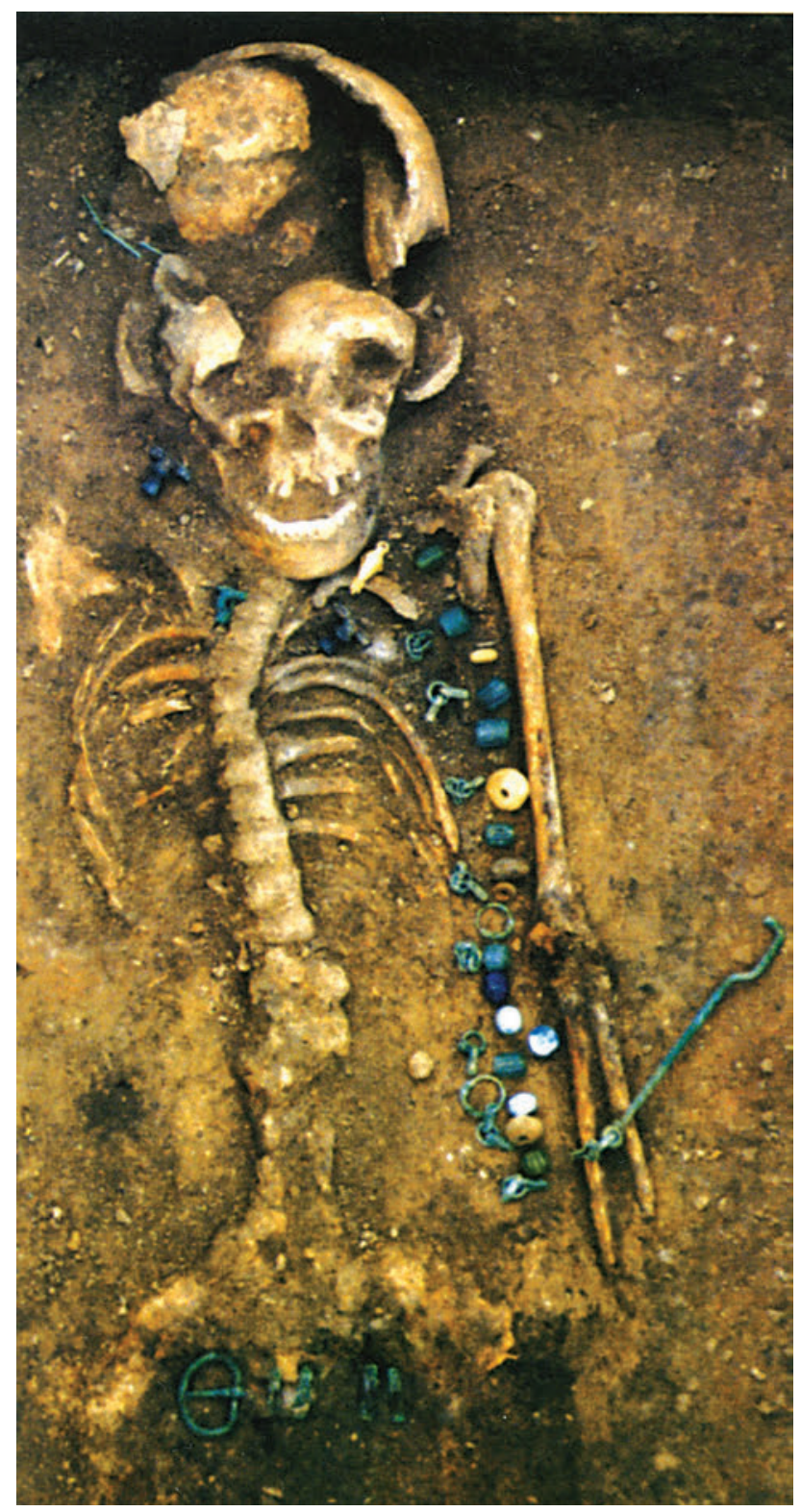

Ryc. 4. Układ paciorków i złącz ogniwkowych odkrytych w grobie 201 na stanowisku w Kowalewku (Adamczyk, Gierlach 2005: 31).

Podobne układy zostały zarejestrowane w grobie 428 w Pruszczu Gdańskim, stan. 10 i pochówku 17A w Cecelach (Tempelmann-Mączyńska 1985a: 270; Jaskanis 1996: 14, tabl. III; Pietrzak 1997: 61-62, tabl. CXXVIII, CLXVI). 
W przypadku dwóch ostatnich obiektów, omawiane zabytki wystąpiły także na poziomie talii osób zmarłych ale bez dodatkowych elementów pasa (ryc. 3: 3, 4; tabl. 3: 1). Paciorki odkryte w grobach z Kowalewka najprawdopodobniej zostały bezpośrednio przymocowane do pasa. Natomiast pozostałe dwa układy zabytków z Pruszcza Gdańskiego, stan. 10 i Cecel wskazują na zastosowanie paciorków jako ozdoby rzemienia, który pierwotnie pełnił funkcję zastępczą pasa.

Jedną z bardziej interesujących form dekoracji z wykorzystaniem paciorków są obszycia torebek lub saszetek. Wyróżnienie tego typu dekoracji zostało podyktowane nietypowymi lecz podobnie jak kolie, zwartymi układami paciorków, które zostały zarejestrowane w nienaruszonych jamach grobowych. W materiale kultury wielbarskiej dwie kompozycje omawianych zabytków można uznać za ozdobne dodatki wspomnianych torebek lub saszetek.

Pierwszy z nich zarejestrowano w grobie 150 na stanowisku w Weklicach, pow. elbląski ${ }^{8}$, drugi w obiekcie 102 na cmentarzysku w Brzynie, stan. 12, pow. pucki (Okulicz-Kozaryn 1992: 143-145, ryc. 7-9; Natuniewicz-Sekuła, Okulicz-Kozaryn 2011: 54-57, tabl. LVIII-LXII, CCXXXVI: 1-6, CCXL: 7, 8, CCXLI: 7-9, CCXLII: 10, 13, 14, CCXLV: 9; Stasiełowicz, Kasprzycka 2016: 84-93; Strobin, Strobin 2018: 138-156). W grobie 102 z Brzyna odkryto 82 paciorki wykonane ze szkła i bursztynu. Zabytki te rozciągały się pionowo od poziomu prawego ramienia do okolic talii (ryc. 2: 4). W dolnej części tego układu paciorki znajdowały się w dość regularnym, prostokątnym układzie. Interpretowanie takiej kompozycji paciorków jako obszycie torebki czy też saszetki jest poświadczone analogicznymi układami ze stanowisk europejskiego Barbaricum. Najbardziej obrazującym przykładem łączenia paciorków w ramach szeroko rozumianej galanterii jest układ zabytków odkryty w inhumacyjnym grobie 2536 w miejscowości Hostivice, okr. Praha-západ w Czechach (Sankot, Theune 2004: 157; 2014: 257-270). W obiekcie tym zlokalizowano 156 paciorków wykonanych ze szkła i bursztynu. Dokładna analiza rozmieszczenia zabytków w jamie grobowej wykazała, że część paciorków wraz z metalowymi kółkami związana była z obszyciem torebki ${ }^{9}$.

Zastanawiającą kwestią jest zastosowanie paciorków jako ozdoby w formie bransoletek. Dotychczas taka kompozycja został odkryta w grobie 92/1898 na stanowisku w Ciepłem, pow. tczewski (Schmidt 1902: 120, tabl. VI: 39, VII: 8, 13, 15a, 15b, 76; Blume 1912: 97; Tempelmann-Mączyńska 1985a: 274; Stanek 1999: 346, ryc. 6). Jest to jak dotąd jedyny przykład wykorzystania paciorków do stworzenia wspomnianej ozdoby.

${ }^{8}$ Uwagi dotyczące interpretacji paciorków odkrytych w grobie 150 z Weklic zostały zawarte w innym artykule (K. Żyto, w druku b).

${ }^{9}$ Podobne uwagi dotyczą zabytków z inhumacyjnego grobu 19 z sarmackiego cmentarzyska Tiszadob-Sziget założonego pod koniec IV w. Odkryty w nim zestaw paciorków łączony jest z obszyciem sakiewki przymocowanej do pasa (Istvánovits 1993: 100, 103; 2001: 143). 


\title{
Podsumowanie
}

Odkrywane masowo paciorki na stanowiskach kultury wielbarskiej określają tę jednostkę mianem ,paciorkowej kultury” (Tempelmann-Mączyńska 1985a: 119). Przedstawione powyżej przykłady jednoznacznie wskazują, że paciorki stanowiły ważny element dekoracji stroju w kulturze wielbarskiej.

Wyróżnienie poszczególnych form zdobniczych było możliwe jedynie w przypadkach, w których zostały zachowane informacje o położeniu paciorków w grobie. W następstwie można wydzielić kolie z paciorków, które były noszone na szyi i mocowane na szatę za pomocą fibul. Następnie należy wskazać aplikacje czyli obszycie szaty lub jej krawędzi za pomocą paciorków. Kolejną formą są ozdobne kompozycje pionowe omawianych zabytków, często łączone z innymi ozdobami wykonanymi z metalu. Dalej można wyróżnić paciorki jako elementy zdobnicze pasa oraz dekoracyjne obszycia saszetek lub torebek.

Problematyczna pozostaje kwestia bransoletek wykonanych z paciorków. Tego typu ozdoba jak dotąd została zarejestrowana w jednym obiekcie na stanowisku w Ciepłem. W przypadku tego cmentarzyska mamy do dyspozycji tylko opisy grobów pozbawionych dokumentacji rysunkowej. Na tej podstawie trudno jednoznacznie zweryfikować czy omawiane zabytki faktycznie należałby wiązać $\mathrm{z}$ ozdobą $\mathrm{w}$ formie bransoletki, czy może np. z elementem zdobniczym pasa.

Podobna uwaga dotyczy kompozycji omawianych zabytków, które miałyby stanowić ozdoby związane z włosami np. w formie wianka. Dotychczas nie został zarejestrowany układ paciorków, który w sposób jednoznaczny wskazywałby na tego typu dekorację.

Niewątpliwie, każda odkrywana w grobach wielbarskich ozdoba wykonana z paciorków jest świadectwem ówczesnych, dobrze ukierunkowanych tendencji oraz szeroko rozprzestrzenionego folkloru. Paciorki znajdowane masowo na cmentarzyskach wielbarskich zarówno w grobach kobiet, dzieci jak i mężczyzn odzwierciedlają stan ogromnego zapotrzebowania na tego typu przedmioty w okresie rzymskim. Omawiane zabytki zajmowały znaczące miejsce w regionalnym stroju ludności wielbarskiej czego dowodem są pasma, które oddają skalę zaangażowania tego społeczeństwa w procesie tworzenia biżuterii.

\author{
Kinga Żyto \\ Instytut Archeologii \\ Uniwersytet Łódzki \\ ul. Narutowicza 65 \\ 90-131 Łódź \\ e-mail: kiniazyto@wp.pl
}




\section{BibLIOGRAFIA}

Adamczyk K., Gierlach M. (2005), The Archaeology of the Transit Gas Pipeline: Idea -Conception - Practice, „Archeologia Żywa”, 2005, s. 28-32.

Barankiewicz B. (1959), Cmentarzysko z okresu rzymskiego w Grodzisku Mazowieckim, „Materiały Starożytne”, t. 5, s. 191-233.

Beilke-Voigt I. (1998), Frühgeschichtlische Miniaturobjekte mit Amulettcharakter zwischen Britischen Inseln und Schwarzem Meer (= Universitätsforschungen zur prähistorischen Archäologie t. 51), Dr Rudolf Habelt Verlag, Bonn.

Blume E. (1912), Die Germanischen Stämme und die Kulturen zwischen Oder und Passarge zur römischen Kaiserzeit: I Text (Mannus - Bibliothek t. 8), Würzburg.

Blume E. (1915), Die Germanischen Stämme und die Kulturen zwischen Oder und Passarge zur römischen Kaiserzeit: II Material (Mannus - Bibliothek t. 14), Würzburg.

Eggers H.J. (1940), Das römische Einfuhrgut in Pommern, „Baltische Studien, Neue Folgen”, t. 42, s. 1-35.

Ethelberg P. (2000), Skovgårde. Ein Bestattungsplatz mit reichen Frauengräbern des 3. Jhs. $n$. Chr. Auf Seeland, Det Kongelige Nordiske Oldskriftselskab, København.

Istvánovits E. (1993), Das Gräberfeld aus dem 4.-5. Jahrhundert von Tiszadob-Sziget, „Acta Archaeologica Academiae Scientiarum Hungaricae”, t. 45, s. 91-146.

Istvánovits E. (2001), Sarmatians through the eyes of strangers: The Sarmatian warrior, [w:] E. Istvánovits, V. Kulcsár (red.), International connections of the Barbarians of the Carpathian Basin in the 1st-5th centuries A. D. proceedings of the International Conference held in 1999 in Aszód and Nyiregyháza, Jósa-AndrásMúzeum, Aszód/Nyíregyháza, s. 139-169.

Jaskanis J. (1996), Cecele. Ein Gräberfeld der Wielbark-Kultur in Ostpolen (= Monumenta Archaeologica Barbarica t. 2), Instytut Archeologii i Etnologii Polskiej Akademii Nauk, Państwowe Muzeum Archeologiczne, Kraków.

Jungklaus E. (1924), Römische Funde in Pommern, Greifswald.

Kmieciński J., Kajzer L., Walenta K. (1968), Odry. Cmentarzysko kurhanowe ze starszego okresu rzymskiego w powiecie chojnickim (= Acta Archaeologica Lodziensia 15), Łódzkie Towarzystwo Naukowe, Zakład Narodowy im. Ossolińskich, Łódź.

Kokowski A. (2004), Goci między Battykiem a Morzem Czarnym, [w:] J. Andrzejowski, A. Kokowski, Chr. Leiber (red.), Wandalowie - strażnicy bursztynowego szla$k u$, Wydawnictwo Uniwersytetu Marii Curie-Skłodowskiej, Lublin-Warszawa, s. 225-252.

Kokowski A. (2006), Starożytna Polska. Od trzeciego wieku przed Chrystusem do starożytności, Wydawnictwo Trio, Warszawa.

Kostrzewski J. (1964), Kolia, [w:] W. Kowalenko, G. Labuda, Z. Stieber (red.), Słownik starożytności słowiańskich, t. 2, F-K, Zakład Narodowy im. Ossolińskich, Wrocław, s. 440.

Kurzyńska M. (2015), Linowo. Stanowisko 6. Birytualne cmentarzysko kultury wielbarskiej z pótnocno-wschodniej części ziemi chetmińskiej, Muzeum Okręgowe w Toruniu, Grudziądz-Torun. 
Łęga W. (1958), Handel między państwem rzymskim a Pomorzem Nadwiślańskim od I w. p.n.e. do VI w. n.e., „,Przegląd Archeologiczny”, t. 10, s. 5-87.

Madyda-Legutko R. (1983), Próba rekonstrukcji pasów z metalowymi czéściami na obszarze środkowoeuropejskiego Barbaricum w okresie wpływów rzymskich i we wczesnej fazie okresu wędrówek ludów, „Przegląd Archeologiczny”, t. 31, s. 91-133.

Mączyńska M. (1972), Uwagi o chronologii i rozprzestrzenieniu paciorków w okresie rzymskim i wczesnej fazie okresu wędrówek ludów, „Archeologia Polski”, t. 17, s. 349-390.

Mączyńska M. (1977), Paciorki z okresu rzymskiego i wczesnej fazy okresu wędrówek ludów na obszarze środkowoeuropejskiego Barbaricum, „Archeologia”, t. 28, s. 61-92.

Natuniewicz-Sekuła M., Okulicz-Kozaryn J. (2011), Weklice, a cemetery of the Wielbark Culture on the Eastern margin of Vistula delta (excavations 1984-2004) (= Monumenta Archaeologica Barbarica t. 17), Fundacja Monumenta Archaeologica Barbarica, Instytut Archeologii i Etnologii Polskiej Akademii Nauk, Państwowe Muzeum Archeologiczne, Warszawa.

Okulicz-Kozaryn J. (1992), Centrum kulturowe z pierwszych wieków naszej ery u ujścia Wisty, „Barbaricum”, t. 2, s. 137-155.

Pietrzak M. (1997), Pruszcz Gdański, Fundstelle 10. Ein Gräberfeld der Oksywie- und Wielbark-Kultur in Ostpommern (= Monumenta Archaeologica Barbarica t. 4), Instytut Archeologii i Etnologii Polskiej Akademii Nauk, Muzeum Archeologiczne w Gdańsku, Kraków.

Pietrzak M. (1998), Dalsze odkrycia na cmentarzysku z późnego okresu wpływów rzymskich i wędrówek ludów w Pruszczu Gdańskim, stan. 5, [w:] E.G. Wilgocki, M. Dworaczyk, P. Krajewski (red.), XII Sesja Pomorzoznawcza: Szczecin 23.-24. października 1997 r.: materiaty (= Acta Archaeologica Pomoranica t. 1), Stowarzyszenie Naukowe Archeologów Polskich, Szczecin, s. 121-126.

Pietrzak M., Cymek L., Rożnowski F. (2015), Pruszcz Gdański stanowisko 5. Cmentarzysko z późnego okresu wpływów rzymskich i wędrówek ludów, Muzeum Archeologiczne w Gdańsku, Gdańsk.

Sankot P., Theune C. (2004), Das germanische Grab 2536 in Hostivice, Okr. Praha-západ, Tschechien, „Germania”, t. 90, s. 145-187.

Sankot P., Theune C. (2014), Das germanische Grab in Hostivice, Befund 2536, und die kaiserzeitlichen Kammergräber in Böhmen, [w:] A. Abegg-Wigg, N. Lau (red.), Kammergräber im Barbaricum (= Schriften des Archäologischen Landesmuseums. Ergänzungsreihe t. 9), Wachholtz Verlag, Neumünster/Hamburg, s. 257-270.

Schmidt A. (1902), Das Gräberfeld von Warmhof bei Mewe, Reg.-Bez. Marienwerder (W. -Pr.), ,Zeitschrift für Ethnologie”, t. 34, s. 97-153.

Skorupka T. (2001), Kowalewko 12. Cmentarzysko birytualne ludności kultury wielbarskiej (od połowy I w. n.e. do początku III w. n. e.), [w:] M. Chłodnicki (red.), Archeologiczne badania ratownicze wzdtuż gazociagu tranzytowego, t. II, Wielkopolska, część 3, Wydawnictwo Poznańskie, Poznań. 
Sobol E. (red.) (1995), Mały Stownik Języka Polskiego, Wydawnictwo Naukowe PWN, Warszawa, s. 323.

Stanek K. (1999), Wisiory opasane odmiany wschodniej w środkowoeuropejskim Barbaricum, [w:] J. Andrzejowski (red.), COMHLAN. Studia z archeologii okresu przedrzymskiego i rzymskiego $w$ Europie Środkowej dedykowane Teresie Dabrowskiej w 65. rocznicę urodzin, Fundacja Przyjaciół Instytutu Archeologii Uniwersytetu Warszawskiego, Warszawa, s. 331-368.

Stasiełowicz G., Kasprzycka M. (2016), Znad Battyku do Rzymu. Katalog wystawy, Muzeum Archeologiczno-Historyczne w Elblągu, Elbląg.

Stawiarska T. (1985), Paciorki szklane z obszaru Polski pólnocnej w okresie wpływów rzymskich (= Biblioteka Archeologiczna 28), Polskie Towarzystwo Archeologiczne i Numizmatyczne, Zakład Narodowy im. Ossolińskich, Wrocław-Warszawa-Kraków-Gdańsk-Łódź.

Strobin A., Strobin J. (2018), Uwagi na temat produkcji bransolet taśmowatych i zapinek A.95 zdobionych foliami z metali szlachetnych na przykładzie zabytków z grobu kultury wielbarskiej w Brzynie, stan. 7, pow. pucki, [w:] B. Niezabitowska-Wiśniewska, P. Łuczkiewicz, S. Sadowski, M. Stasiak-Cyran, M. Erdrich (red.), Studia Barbarica Profesorowi Andrzejowi Kokowskiemu w 65. rocznice urodzin, t. I, Wydawnictwo UMCS, Lublin, s. 138-156.

Tempelmann-Mączyńska M. (1985a), Die Perlen der römischen Kaiserzeit und der frühen Phase der Völkerwanderungszeit im mitteleuropäischen Barbaricum (= Römisch-Germanische Forschungen t. 43), Deutsches Archäologisches Institut, Römisch-Germanische Kommission, Mainz am Rhein.

Tempelmann-Mączyńska M. (1985b), Części stroju kobiecego w okresie rzymskim na obszarze środkowo- $i$ wschodnioeuropejskiego Barbaricum (= Rozprawy Habilitacyjne t. 98), Uniwersytet Jagielloński, Kraków.

Tempelmann-Mączyńska M. (1989), Das Frauentrachtzubehör des mittel- und osteuropäischen Barbaricums in der römischen Kaiserzeit, Jagiellonen-Universität, Kraków.

Tischler O. (1879), Ostpreussische Gräberfelder III, Königsberg.

Tuszyńska M. (2003), Wielokulturowe cmentarzysko płaskie w Opaleniu, gmina Gniew, stanowisko 1, [w:] M. Fudziński, H. Paner (red.), XIV Sesja Pomorzoznawcza, vol. 1, Od epoki kamienia do okresu rzymskiego, Muzeum Archeologiczne w Gdańsku, Gdańsk, s. 303-309.

Tuszyńska M. (2005), Ulkowy. Cmentarzysko kultury wielbarskiej na Pomorzu Gdańskim, Muzeum Archeologiczne w Gdańsku, Gdańsk.

Tuszyńska M. (2007), Nowe znaleziska zapinek importowanych na Pomorzu Gdańskim, [w:] M. Fudziński, H. Paner (red.), Nowe materiaty i interpretacje. Stan dyskusji na temat kultury wielbarskiej, Muzeum Archeologiczne w Gdańsku, Gdańsk, s. $139-150$.

Tuszyńska M. (2010), Interesujący pochówek kobiecy z cmentarzyska w Kamienicy Szlacheckiej na Pojezierzu Kaszubskim, [w:] A. Urbaniak, R. Prochowicz, I. Jakubczyk, M. Levada, J. Schuster (red.), Terra Barbarica. Studia ofiarowane Magdalenie Mączyńskiej w 65 rocznice urodzin (= Monumenta Archaeologica 
Barbarica. Series Gemina t. 2), Instytut Archeologii Uniwersytetu Łódzkiego, Fundacja Uniwersytetu Łódzkiego, Fundacja Monumenta Archaeologica Barbarica, Państwowe Muzeum Archeologiczne w Warszawie, Łódź-Warszawa, s. 489-496.

Tuszyńska M., Strobin A., Strobin J. (2016), Rzemieślnicy czy artyści? Ozdoby kobiece z Pomorza u schytku starożytności. Katalog skrócony wystawy, Muzeum Archeologiczne w Gdańsku, Gdańsk.

Wołągiewicz R. (1981), Kultura oksywska i wielbarska, [w:] J. Wielowiejski (red.), Prahistoria ziem polskich, t. 5, Wydawnictwo Polskiej Akademii Nauk, Wrocław-Warszawa-Kraków-Gdańsk, s. 135-190.

Wołągiewicz R. (1995), Lubowidz. Ein birituelles Gräberfeld mit der Wielbark-Kultur aus der Zeit vom Ende des 1. Jhs. v. Chr. Bis zum Anfang des 3. Jhs. n. Chr. (= Monumenta Archaeologica Barbarica t. 1), Instytut Archeologii i Etnologii Polskiej Akademii Nauk, Muzeum Narodowe w Szczecinie, Kraków.

Żyto K. (w druku a), Kolia w kulturze wielbarskiej. Studia nad jednym elementem stroju kobiecego.

Żyto K. (w druku b), Nie tylko kolia. Alternatywna propozycja rekonstrukcji pasm paciorków odkrytych w grobie 150 w Weklicach, pow. elbląski.

\section{SUMMARY}

\section{COSTUME DECORATIONS MADE OF BEADS IN WIELBARK CULTURE}

The main purpose of the article is to present various forms of costume decoration in Wielbark culture. The analysis was based on well-known burials with an intact arrangement of monuments in the burial cavern. On this basis, decorations made of beads were highlighted. In addition to the necklaces that adorned the area of the neck and chest, vertical compositions are particularly noteworthy, in which the beads were discovered in a line from the level of the neck to the waist level. In addition, beads were used to trim robes in the form of applications. Another type are beads decorating belt and sachets or purses. 


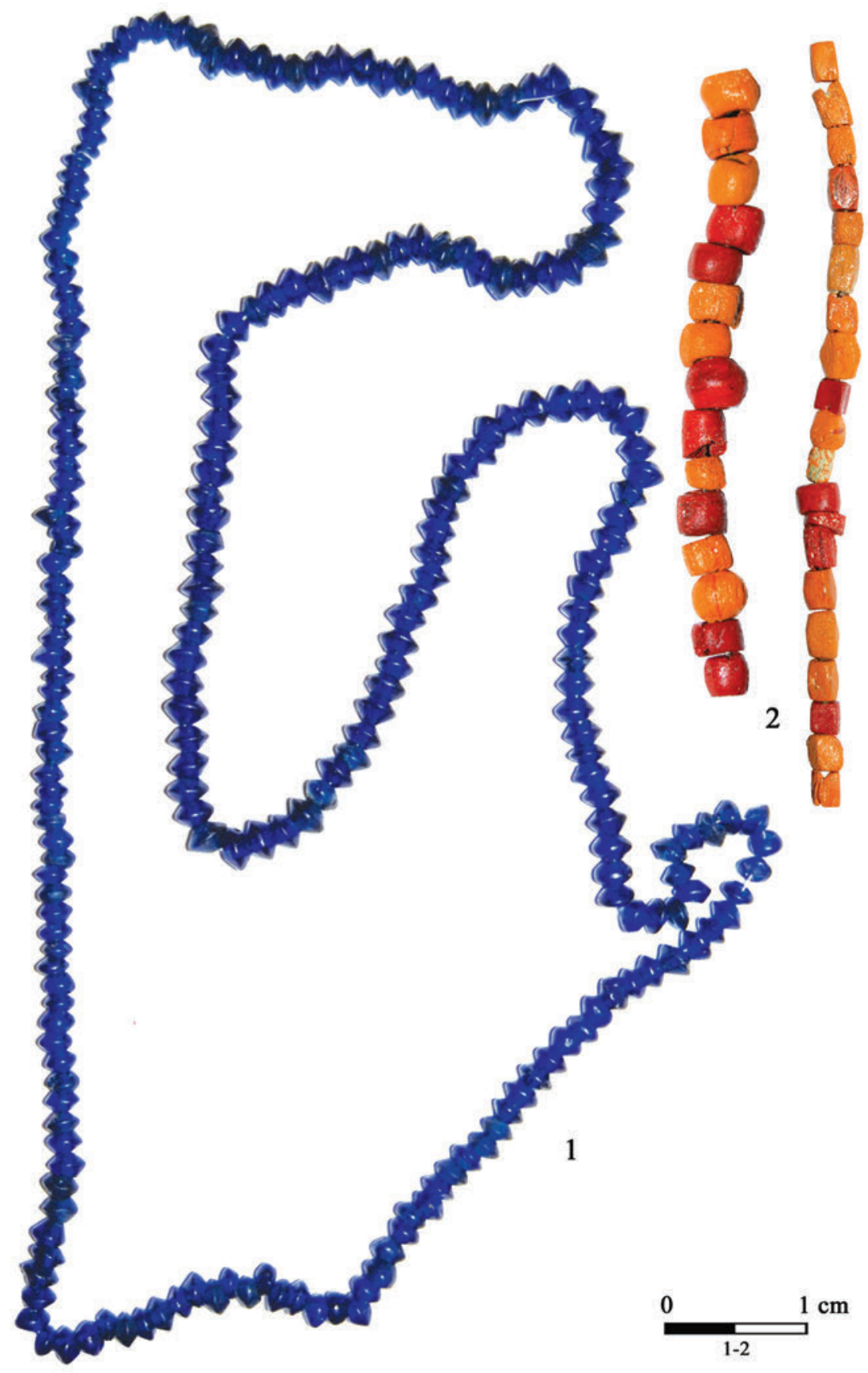

Tabl. 1. Szklane paciorki wchodzące w skład aplikacji odkryte w grobie 12 na stanowisku 5 w Pruszczu Gdańskim (fot. K. Żyto, zbiory Muzeum Archeologicznego w Gdańsku). 


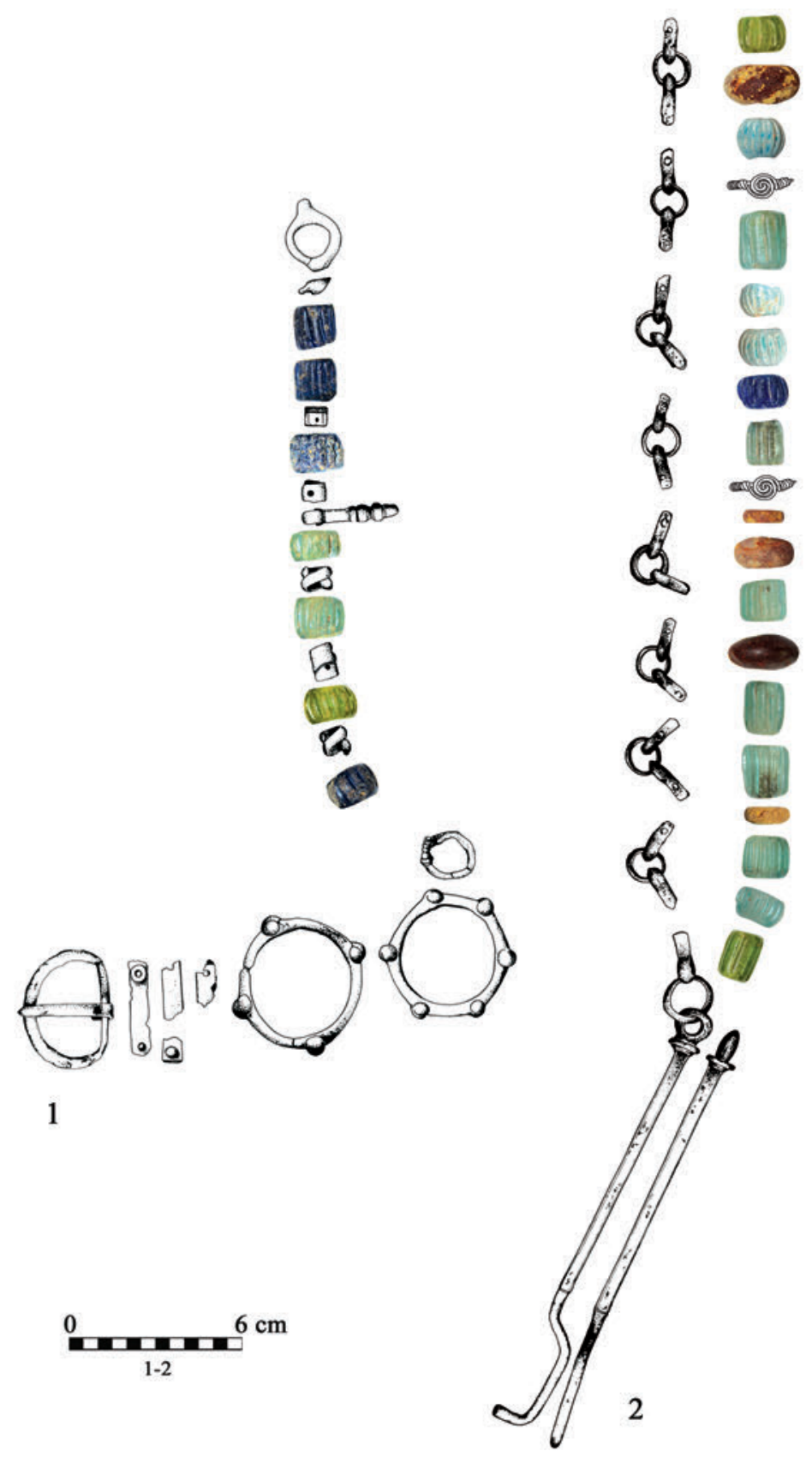

Tabl. 2. Szklane i bursztynowe paciorki wchodzące w skład pionowych kompozycji. 1. Kowalewko, grób 282; 2. Kowalewko, grób 201 (rekonstrukcje na podstawie tablic: Skorupka 2001: 62, 63, 85 oraz fot. K. Żyto, zbiory Muzeum Archeologicznego w Poznaniu). 

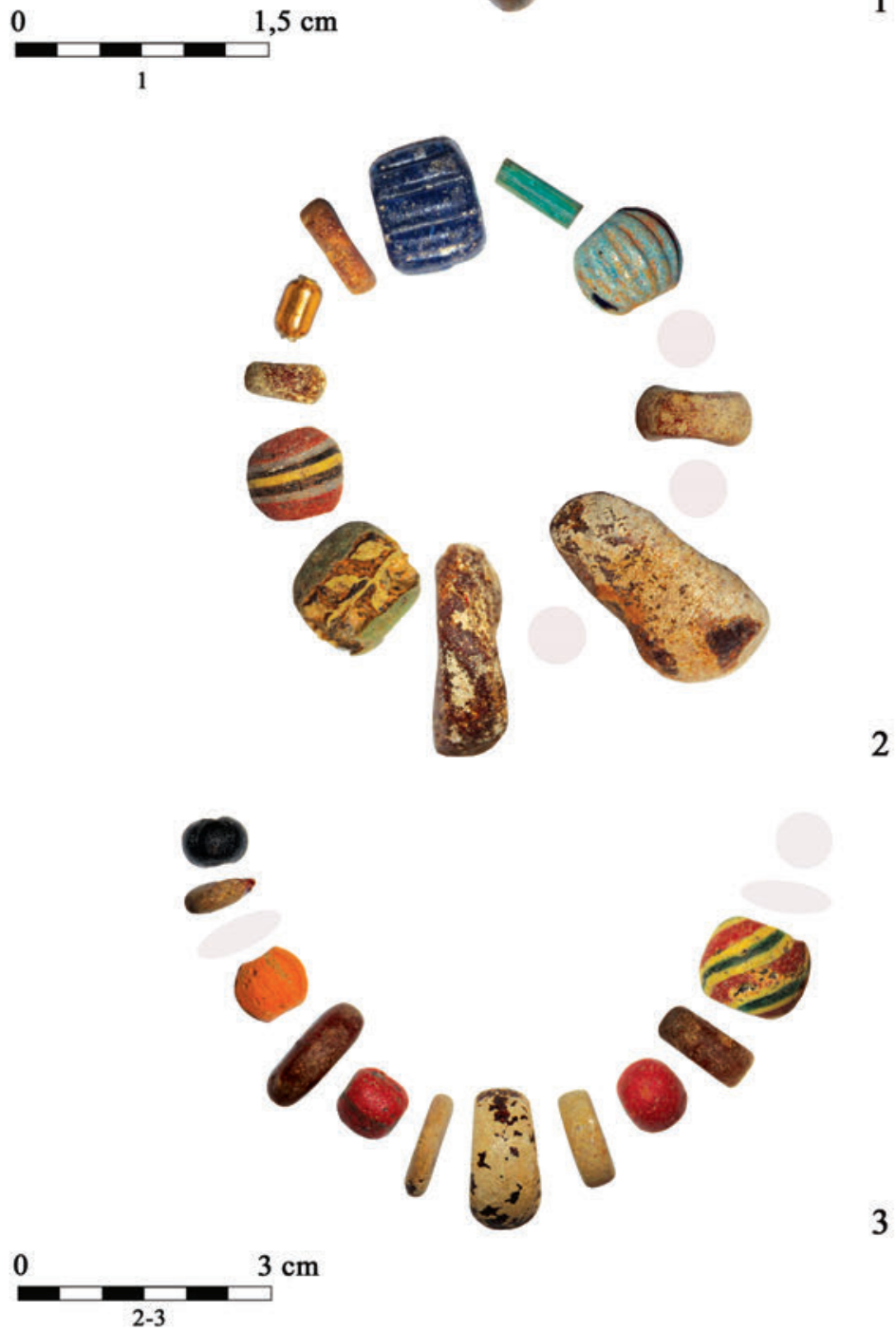

Tabl. 3. Szklane i bursztynowe paciorki wchodzące w skład elementów dekoracyjnych pasa. 1. Cecele, grób 17A; 2. Kowalewko, grób 87; 3. Kowalewko, grób 223 (fot. K. Żyto, zbiory Muzeum Archeologicznego w Poznaniu oraz Muzeum Podlaskiego w Białymstoku). 